Documenta \& Instrumenta

ISSN-e: 1697-3798

http://dx.doi.org/10.5209/DOCU.64059

\title{
O Ceitil. Um símbolo da Modernidade portuguesa e a sua evolução estética (1440’-1570’)
}

Tiago Gil Curado ${ }^{1}$

Recibido: 10 de julio de 2018 / Aceptado: 3 de abril de 2019

Resumen. A história e evolução estética da moeda que é um símbolo da Modernidade portuguesa desde meados do século XV até à segunda metade do século XVI. Sendo a tipologia mais presente nos contextos arqueológicos de Lisboa mas ao mesmo tempo facilmente deteriorável, importa retirar a máxima informação dos exemplares menos conservados.

Palabras clave. Ceitil; Numismática; modernidade; Portugal.

[en] Ceitil. A symbol of modernity and its aesthetical evolution (1440'1570 ').

Abstract. The history and the aesthetical evolution of a coin that is a symbol of the Portuguese Modernity between the mid-15th century and the second half of the 16th century. Since the Ceitil is the most common coin is archaeological excavations and at the same time easily degradable, it is very important to get as much information as possible from the less preserved coins.

Keywords. Ceitil; Numismatic; modernity; Portugal.

Sumario. 1. D. Afonso V (1438-1481). 2. D. João II (1481-1495). 3. D. Manuel I (1495-1521). 4. D. João III (1521-1557). 5. D. Sebastião (1557-1578). 6. Bibliografia.

Cómo citar: T. Gil Curado, "O Ceitil. Um símbolo da modernidade portuguesa e a sua evolução estética (1440'-1570')”, Documenta \& Instrumenta, 17 (2019), pp. 19-31. 
O presente artigo resulta de um estudo arqueológico onde foi feito o levantamento do espólio numismático proveniente de 62 escavações na cidade de Lisboa. Entre as quase 4.000 moedas inventariadas 867 eram Ceitis.

O Ceitil será abordado aqui tendo com foco na sua passagem na história de Portugal assim como a evolução estética que sofreu ao longo dos seus mais de 120 anos de cunhagem.

Durante a história da numismática, o conceito de Ceitil, ou a catalogação como Ceitil, não foi sempre unânime. Alguns autores do século XIX tais como Teixeira de Aragão ${ }^{2}$ ou Ferreira Braga ${ }^{3}$ assumiam o aparecimento do Ceitil no reinado de D. João I (1385-1433) e sua contínua cunhagem até ao reinado de D. Sebastião (15571578). O motivo que levou a considerar antecipadamente o início da moeda prende-se com dois factores: o facto de D. João I ter conquistado a cidade de Ceuta em 1415 (reforçando a teoria a etimologia da palavra - Ceitil $\approx$ Ceuta) e de se afirmar conhecer-se uma moeda em mau estado de conservação cunhada por D. João I com o que parecem ser letras árabes. Porém nunca foi comprovada a existência dessa mesma moeda e por outro lado a origem da palavra Ceitil também pode derivar por esta, em tempo de D. Afonso V (1438-1481), valer um sexto ( $\approx$ ceisto $)$ da moeda de Real Branco, unidade do sistema monetário de então ${ }^{4}$. Hoje em dia, mais do que uma justificação histórica, atribui-se a nomenclatura de Ceitil a todas a moedas que correspondam a umas distintas características físicas: Ceitil é toda a moeda de cobre, em cujo reverso é possível observar o escudo português centrado, rodeado por uma legenda que pode conter ou não o nome do monarca, e onde no anverso desta se destaca um castelo de três torres com muralha em redor, sobre umas ondas marítimas na esmagadora maioria das vezes, rodeado também por uma legenda ${ }^{5}$. Cobre, escudo e castelo; as três palavras que definem o Ceitil. É com base nestes atributos que à luz de hoje em dia se cataloga este numisma e com os quais se rege o presente estudo.

Ainda que se desconheça hoje em dia o ano em que se iniciou a cunhagem do Ceitil, é certamente no reinado de $\mathrm{D}$. Afonso $\mathrm{V}$ que surgem as primeiras cunhagens. Esta moeda nasce numa época de forte recuperação económica depois dos ruinosos reinados de D. Fernando e D. João $\mathrm{I}^{6}$. As fortes reformas económicas feitas por D. Duarte (1433-1438) aliadas às crescentes importações ultramarinas africanas, fizeram cair todas as moedas de bolhão cunhadas nas anteriores quatro décadas para arrecadar receitas de senhoriagem e que em muito danificavam a economia nacional ${ }^{7}$. Foi nessa restruturação monetária, já com D. Afonso V, que surgiu pela primeira vez a moeda de cobre enquanto moeda de troco sólida, quebrando com a tradição medieval, desde a fundação do reino, de apenas se emitirem moedas de troco em bolhão. $\mathrm{O}$ reinado de $\mathrm{D}$. Afonso $\mathrm{V}$ foi verdadeiramente a transição para a modernidade monetária. Durante o seu reinado ainda se emitiram os Meios Reais Pretos em cobre iniciados por D. João I e algumas moedas em bolhão também como continuação do numerário dito rei. Inclusive as próprias moedas de D.

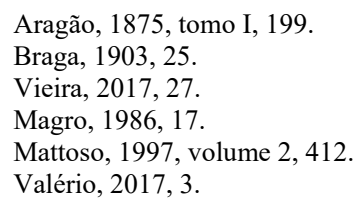


Afonso $\mathrm{V}$ ainda apresentavam as letras com o estilo gótico ${ }^{8}$. Todas essas remanescências medievais foram totalmente abolidas por D. João II (1481-1495). Erradicou os Reais Pretos, todas as moedas de bolhão, e ainda renovou em carta régia a estética do Ceitil, retirando a Cruz de Avis do escudo português ${ }^{9}$ e atribuindo uma letra renascentista.

É no reinado de D. Manuel I que surge a única excepção à matriz estética do Ceitil. Este, que seguramente seria uma emissão exclusiva para os domínios portugueses no norte de África, apresentava no centro do anverso a frase em árabe "De Manuel Reis de Portugal" e no reverso apenas as armas reais coroadas ${ }^{10}$ (Ilustração 1). Não se conhecem aos dias de hoje exemplares semelhantes emitidos por outros monarcas.
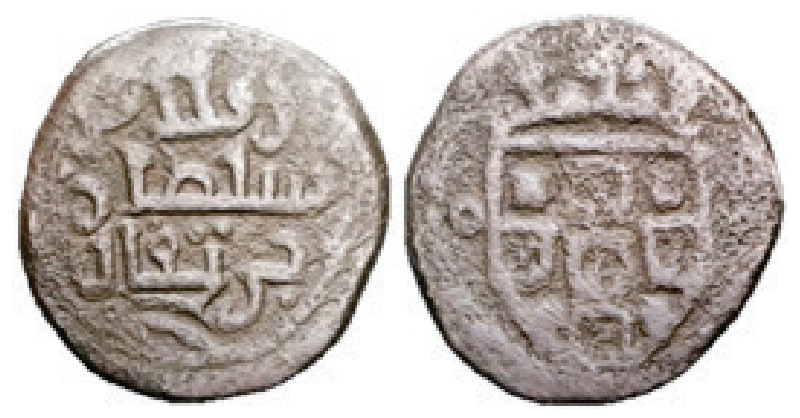

Ilustração 1. Ceitil de D. Manuel I em árabe ${ }^{11}$.

O Ceitil como moeda de troco continuou a ser cunhada ininterruptamente até ao reinado de D. Sebastião. Contudo com o passar do tempo, a própria economia ia evoluindo e a inflação acabou por empurrar o Ceitil para um valor cada vez mais irrelevante. Como tal houve a necessidade de acrescentar novas moedas de cobre, sobretudo a partir do reinado de D. João III (1521-1557) para suprir as necessidades do comércio ${ }^{12}$. Ainda assim, a sua produção não foi descontinuada até ao final da Segunda Dinastia portuguesa.

Na década de 60 do século XVI, durante o reinado de D. Sebastião, descobriuse no reino uma enorme quantidade de moedas de cobre contrafeitas, nomeadamente as de V Reais, causando um grande transtorno à economia nacional ${ }^{13}$. Relatam as fontes históricas que eram de uma tal perfeição que se tornava praticamente impossível distinguir das originais. As respostas para combater a circulação das falsas moedas foram várias desde a suspensão temporal de alguns tipos monetários, à alteração das dimensões das novas moedas, até que, por total incapacidade de controlo, D. Sebastião ordenou a alteração do valor da moeda de 10 Reais para 3 Reais, a de 5 Reais para 1 Real e meio, a de 3 Reais para 1 Real e a de 1 Real para

\footnotetext{
Gomes, 2006, 122.

Resende, 2007, 89.

Curado, 2015, 172

Curado, 2015, 173.

Gomes, 2006, 166.

Godinho, 1981, 12.
} 
Meio Real ${ }^{14}$. A dita ordenação não faz menção ao Ceitil. Esse facto pode ter três justificações; a grande liquidez monetária e consequente subida de preços podiam ter iniciado uma maior e irreversível desvalorização do Ceitil; a redução das dimensões monetárias poderia ter justificado a suspensão pontual da produção constante do Ceitil uma vez que este já tinha um tamanho bastante reduzido; e finalmente, com o último recurso de desvalorização em mais de $50 \%$ do valor facial das moedas, teria afastado definitivamente o Ceitil uma vez que não havia moedas com valores abaixo deste.

O Ceitil não resistiu à vaga de moedas contrafeitas introduzidas em Portugal na década de 60 do século XVI e não voltou a ser produzida. Foi a única moeda de cobre a ser descontinuada da Segunda para a Quarta Dinastia. Ainda assim, o seu período útil de vida estende-se até ao reinado de D. João IV (1640-1656), uma vez que D. António (1580) revogou e repôs os valores iniciais das moedas de cobre ${ }^{15}$, e por outro lado, a ausência de cunhagem em cobre durante a Dinastia Filipina (1580-1640), obrigou a uma reutilização do numerário antigo.

Tal como hoje em dia, todas as moedas transportam mensagens e estas tendem a ser de teor político. Sendo o Ceitil uma moeda de troco, de baixo valor comercial, a sua massificação deu a conhecer mais facilmente à população (portuguesa e magrebina) do século XV e XVI, não só o nome do rei vigente, mas também termos como Ceuta e Guiné. Como tal, considera-se o Ceitil como um objecto chave deste período histórico expansionista, não só pelo efeito de familiarização social com as novas políticas ultramarinas mas também, tal como foi referido anteriormente, ser um símbolo do regresso à estabilidade e o início de um período de prosperidade económica.

$\mathrm{Na}$ interpretação dos contextos arqueológicos os numismas representam um papel muito importante para a datação relativa, porém infelizmente nem sempre estes objectos se encontram em condições ideais para que se possa fazer alguma leitura. Em alguns casos as moedas são apenas aglomerados de óxido e noutros casos apenas se consegue observar uma pequena parte das suas características. No caso do universo numismático identificado para o presente estudo, os Ceitis representam o maior conjunto inventariado de toda a monarquia portuguesa. Estas são moedas de cobre de cunho manual, o que as torna mais vulneráveis à degradação, como tal qualquer informação que seja possível identificar nas suas faces pode fazer a diferença no que toca à afinação de cronologias. O Gráfico 1 mostra dos 867 Ceitis inventariados segundo a sua cronologia mais exacta apurável de acordo com o seu grau de conservação.

Dado que o Ceitil foi sofrendo alterações estéticas e fisionómicas, explicadas mais adiante, é possível agrupar elementos com menor grau de leitura em intervalos temporais mais curtos. A última coluna do Gráfico 1 concentra todos os numismas que por extrema degradação apenas foi possível atribuir a tipologia. 


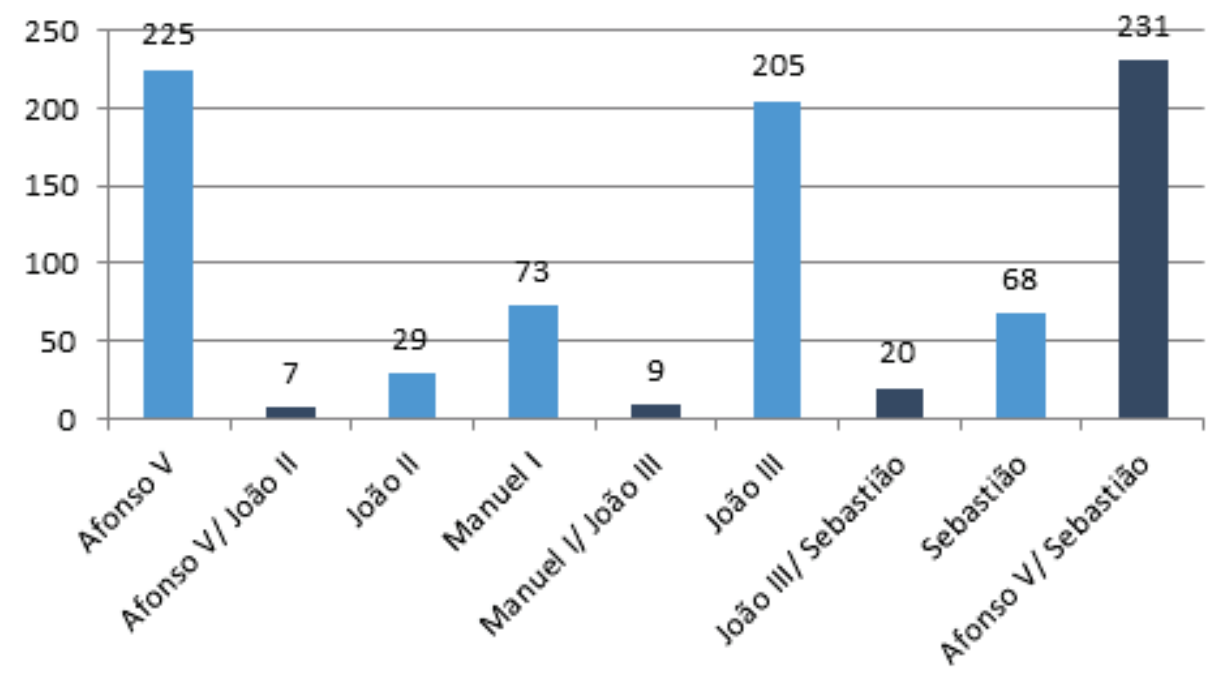

Gráfico 1. Distribuição cronológica dos Ceitis.

Ainda que estas moedas tenham períodos de vida que ultrapassam os 100 anos, o facto de um conjunto monetário arqueológico contar apenas com moedas de D. Afonso V e D. João II, por exemplo, é possível afirmar que a sua deposição não tenha sido posterior ao século XV. Por outro lado, se por exemplo uma colecção numismática proveniente de contextos arqueológicos for composta por moedas de D. Afonso V, D. João II e D. Sebastião, já a atribuição de cronologias para a deposição terá que ser alargada desde meados do século XVI até meados do século XVII. Como tal é de extrema importância atribuir a cronologia mais exacta possível.

É necessário ter em conta que o Ceitil foi cunhado de forma massiva em diversas cidades de Portugal e do norte de África ${ }^{16}$ com diversos cunhos em cada Casa da Moeda. Esta enorme variabilidade e a total ausência de fontes históricas tornam impossível prever todas as variantes emitidas. Contudo através de uma análise muito detalhada é possível criar tipologias distintivas de cada reinado. Serve o seguinte ponto para auxiliar a identificação cronológica de Ceitis com estados de degradação mais elevados. A presença dos desenhos que acompanham os exemplares fotografados corresponde a um auxílio na identificação das suas características para as imagens onde estas se encontrem mais degradadas.

\section{D. Afonso V (1438-1481)}

Foi o primeiro em cunhar Ceitis. O documento mais antigo que se conhece que refere às ditas moedas data de 1449, portanto é possível afirmar que esta tipologia só tenha surgido na segunda metade da década de 40 do século $\mathrm{XV}^{17}$. As suas 
moedas são as maiores, as mais detalhadas e as que apresentam maior variabilidade. A descrição baseia-se nos exemplares inventariados no catálogo de Alberto Gomes ${ }^{18}$.
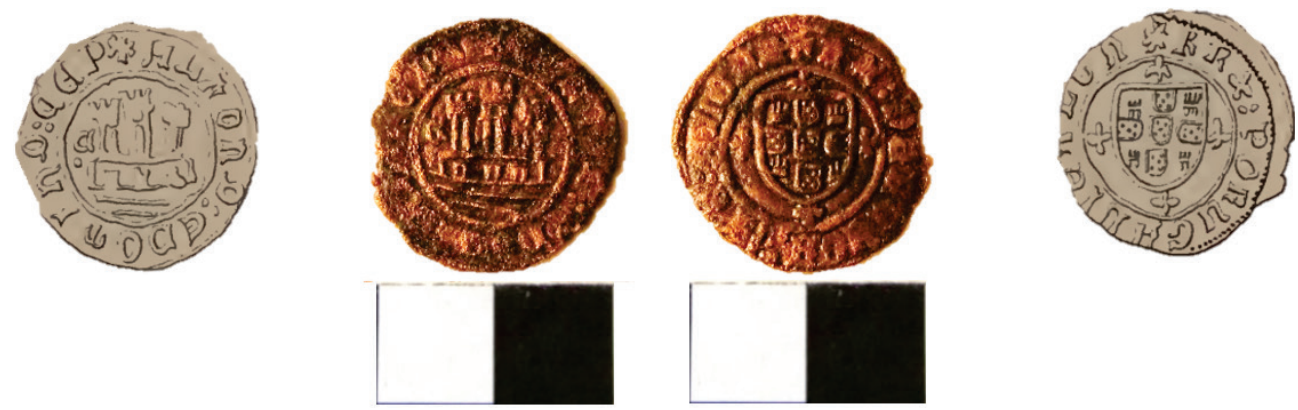

Ilustração 2. Anverso e Reverso de Ceitil de D. Afonso V da escavação dos Terraços do Carmo (TC13-A-1252-1) e desenho de Teixeira de Aragão ${ }^{19}$.

$\underline{\text { Tamanho }}$

$\underline{\text { Peso }}$

Legenda

$\underline{\text { Letra }}$

$\underline{\text { Castelo }}$

$\underline{\text { Ondas }}$

$\underline{\text { Escudo }}$
$23 / 26 \mathrm{~mm}$.

$1.93 / 1.54 \mathrm{~g}$.

Inicia maioritariamente com uma cruz "+" ou também com ":" ou ".". Os diagramas abaixo indicam a maioria das possíveis combinações de palavras nas legendas de ambas as faces nos Ceitis ao longo do tempo.
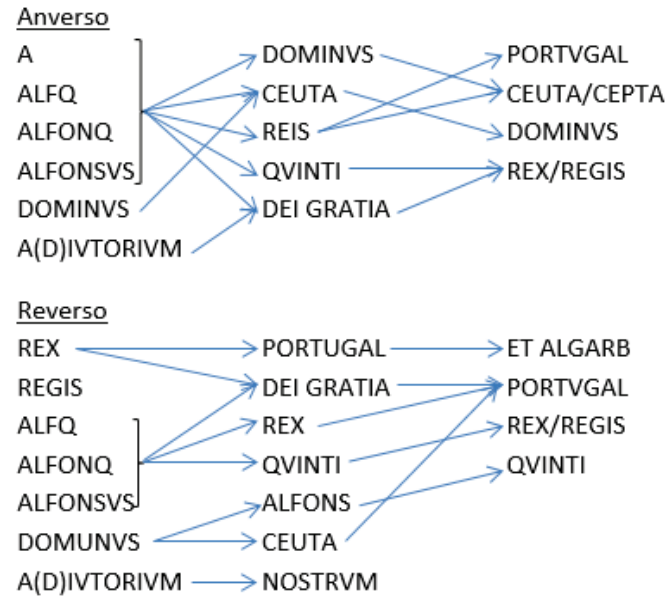

Gótica.

Três torres com ameias e muralha em redor.

2 a 5 linhas onduladas.

Sobre a Cruz de Avis - só é possível ver as pontas dos braços com a florde-lis. $\mathrm{O}$ escudo tem 5 escudetes e 4 castelos. A base do escudo é pontiaguda. 
Letra de cunho Nalguns exemplares de D. Afonso V encontram-se letras da cidade de cunhagem; L - Lisboa, P - Porto, C - Ceuta e A - Alcáçar-Ceguer ou Arzila $^{20}$. Este tipo de marcas nos Ceitis é exclusivo deste reinado. $\mathrm{Na}$ moeda da fotografia da Ilustração 2 encontra-se à esquerda da primeira torre do castelo a letra de cunho " $\mathrm{C}$ ".

\section{D. João II (1481-1495)}

Durante este período cunhou-se uma pequena variedade de Ceitis.
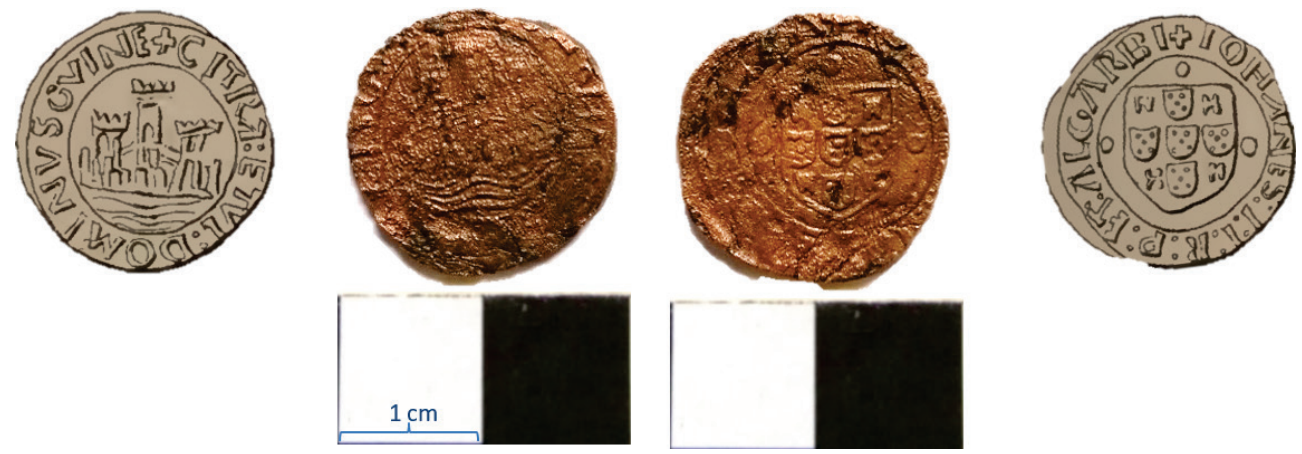

Ilustração 3. Anverso e Reverso de Ceitil de D. João II da escavação da Praça da Figueira (PF00-I/J-10/11-4038-1) e desenho de Teixeira de Aragão ${ }^{21}$.

Tamanho $\quad \pm 20 \mathrm{~mm}$.

Peso $\quad 1,3 / 2 \mathrm{~g}$.

Legenda Começa com uma cruz “+”.

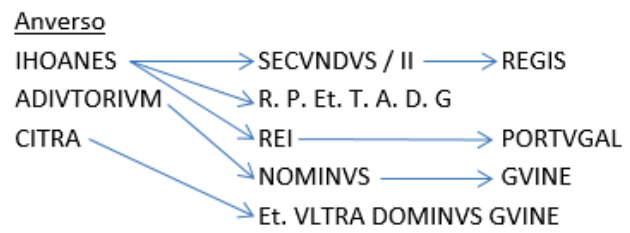

Reverso

$\begin{array}{ll}\text { IHOANES } \longrightarrow \text { SECVNDVS } / I I & \longrightarrow \text { REIS } \longrightarrow \text { PORTVGAL } \\ \text { CI. Et. VL. DOMINVS GVINE } & \text { R. P. Et. ALG } \rightarrow \text { D.G } \\ \text { ADIVTORIVM NOSTRVM } & \end{array}$

Letra Renascentista, por vezes com algumas letras Góticas.

Castelo Três torres com ameias e muralha em redor.

Ondas Maioritariamente 3 linhas onduladas. 
Escudo $\quad \mathrm{O}$ escudo tem 5 escudetes e 4 castelos. A base do escudo é pontiaguda e em redor deste encontram-se normalmente pequenos círculos "o" intitulados aneletes.

\section{D. Manuel I (1495-1521)}

Durante este período houve alguma diversidade na emissão.
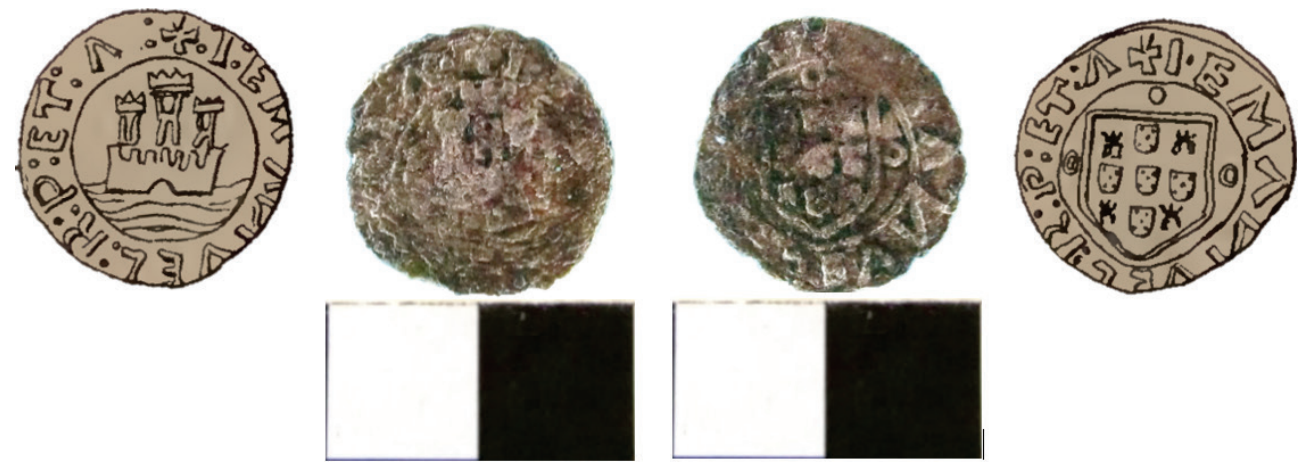

Ilustração 4. Anverso e Reverso de Ceitil de D. Manuel I da escavação do Largo do Coreto em Carnide (LCOR12-24-XXVII-24234-1) e desenho de Teixeira de Aragão ${ }^{22}$.

$\underline{\text { Tamanho }} \quad \pm 20 \mathrm{~mm}$.

Peso $\pm 1,9 \mathrm{~g}$.

Legenda Começa com uma cruz “+”.

Anverso

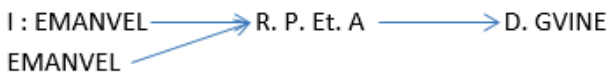

Reverso

I: EMANVEL $\longrightarrow$ R. P. Et. A $\longrightarrow$ D. GVINE
EMANVEL

Letra Renascentista.

Castelo $\quad$ Três torres com ameias e muralha em redor. $\mathrm{O}$ castelo perde detalhe.

Ondas 2/3 linhas onduladas.

Escudo $\quad \mathrm{O}$ escudo tem 5 escudetes e 4 castelos. A base do escudo é pontiaguda e em redor deste encontram-se normalmente pequenos círculos " "intitulados aneletes.

22 Aragão, 1875, tomo I, 499. 


\section{D. João III (1521-1557)}

Durante este período cunhou-se uma grande diversidade de Ceitis.
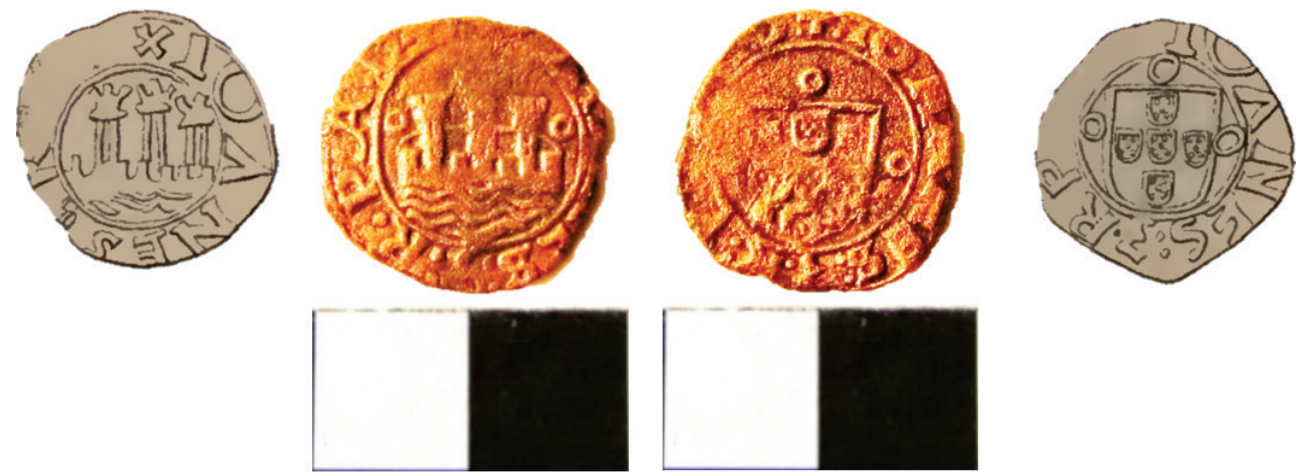

Ilustração 5. Anverso e Reverso de Ceitil de D. João III da escavação dos Terraços do Carmo (TC13-A-1235-2) e desenho de Teixeira de Aragão ${ }^{23}$.

Tamanho $\pm 17 \mathrm{~mm}$.

Peso $\quad 1,4 / 2,4 \mathrm{~g}$.

Legenda Inicia com uma cruz “+” ou “:”. Em muitos exemplares a legenda surge parcial ou totalmente cortada.
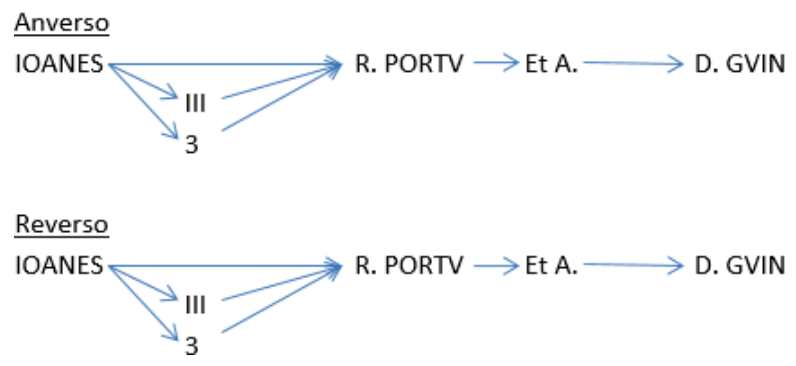

Letra Renascentista.

Castelo $\quad$ Três torres com ameias e muralha em redor. O castelo perde mais detalhe e a muralha aumenta de tamanho.

Ondas $\quad 1 / 3$ linhas onduladas.

Escudo $\quad O$ escudo tem 5 escudetes mas nem sempre tem os 4 castelos. A base do escudo é curva e em redor deste encontram-se normalmente pequenos círculos " "intitulados aneletes.

Alguns exemplares já não contêm o anel que separa o campo central da legenda. Quase $30 \%$ dos Ceitis de D. João III identificados nos contextos arqueológicos de Lisboa apresentavam uma forma quadrangular.

23 Aragão, 1875, tomo I, 507. 


\section{D. Sebastião (1557-1578)}

Durante este período cunhou-se pouca diversidade de Ceitis.
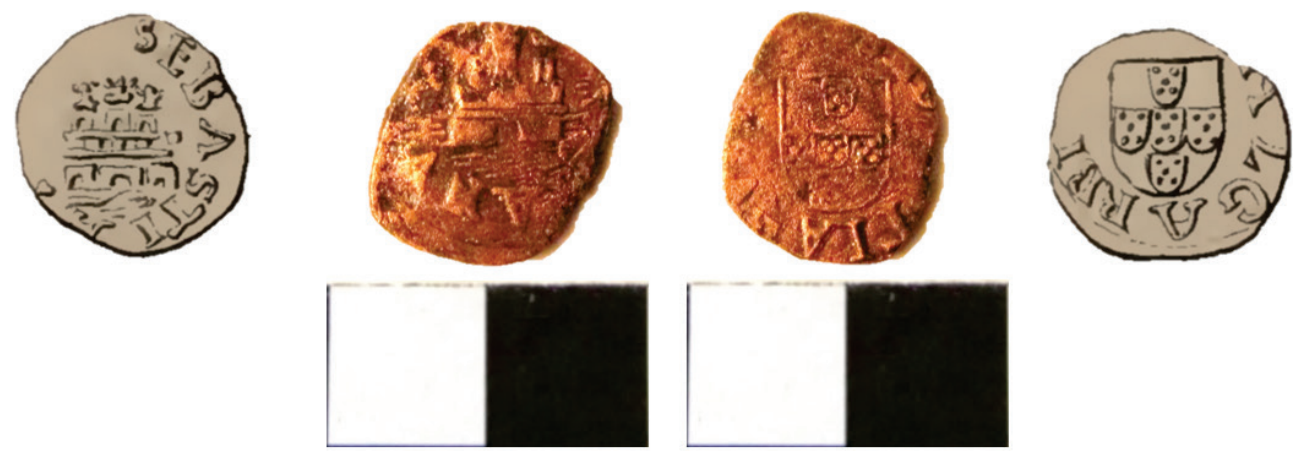

Ilustração 1. Anverso e Reverso de um Ceitil de D. Sebastião da escavação dos Terraços do Carmo (TC13-A-1235-1) e desenho de Teixeira de Aragão ${ }^{24}$.

$\underline{\text { Tamanho }}$

Peso

Legenda

$\underline{\text { Letra }}$

Castelo

$\underline{\text { Ondas }}$

$\underline{\text { Escudo }}$

$12 / 17 \mathrm{~mm}$.

$0,9 / 1,9 \mathrm{~g}$.

Inicia maioritariamente com “.”.

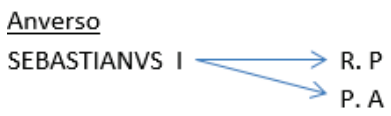

Reverso

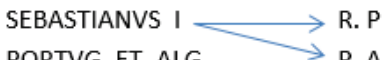

PORTVG. ET. ALG $\longrightarrow$ P.A

\section{Renascentista.}

Três torres com ameias e muralha em redor. O castelo perde mais detalhe e a muralha aumenta de tamanho.

Com pequenas linhas onduladas ou mesmo sem ondas.

$\mathrm{O}$ escudo tem 5 escudetes e não tem os 4 castelos. A base do escudo é curva.

Desaparece o anel que separa o campo central da legenda.

Quase $12 \%$ dos Ceitis de D. Sebastião identificados nos contextos arqueológicos de Lisboa apresentavam uma forma quadrangular. O que se observa na descrição dos Ceitis ao longo do tempo é que a moeda foi perdendo o detalhe das suas características assim como o seu cuidado estético. 

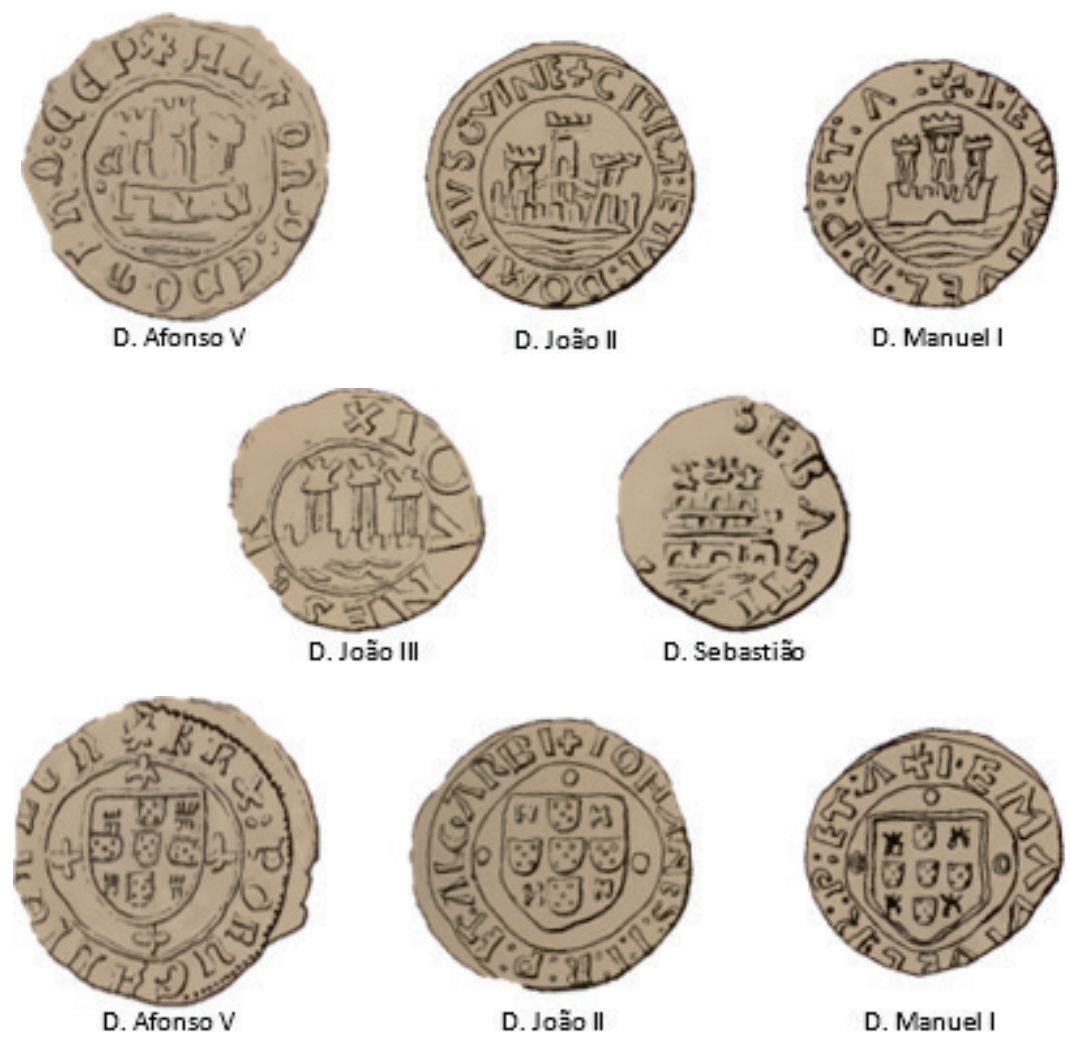

D. Manuel I
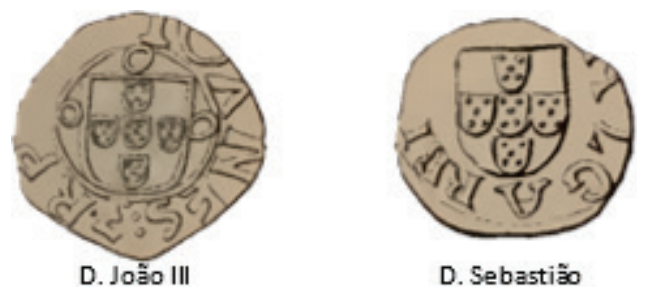

Ilustração 7. Anverso e Reverso de um exemplar de cada reinado em que se cunharam Ceitis $^{25}$.

Devido à consistência do próprio objecto, estes numismas são de difícil conservação em contextos arqueológicos. Nos mais de 850 exemplares observados para a presente base de dados, apenas 25 mereceram uma referência de boa conservação. De resto as fotografias aqui apresentadas correspondem aos numismas considerados com melhores leituras, e ainda assim não é possível observá-los integralmente. Conhecer cada característica física do Ceitil permite que cada vez mais a barra referente ao conjunto com a baliza cronológica mais alargada vá diminuindo.

Resumidamente observaram-se alterações ao longo do tempo nos seguintes pontos: 
- Tamanho e peso: desde D. Afonso V até D. Sebastião, o Ceitil perdeu mais de $1 \mathrm{~cm}$ de diâmetro e consequentemente no seu peso também. Para os numismas de cobre provenientes de escavações arqueológicas, o peso que apresentam não é um bom indicador, uma vez que podem conter concreções de óxido ou até falhas na sua superfície, o que inviabiliza uma leitura fiável. É mais recomendável o controlo do diâmetro e quanto mais pequeno este for, mais recente será a moeda.

- Legenda: A informação escrita em cada Ceitil foi sendo cada vez mais reduzida ao longo do tempo. A diversidade e variabilidade de legendas de D. Afonso V mas também de D. João II, contrasta com a simplicidade que adquire a partir do reinado de D. Manuel I, até destacar praticamente apenas nome do soberano com D. Sebastião. Termos como "DOMINVS", "ADIVTORIVM NOSTRVM" ou "CEUTA" caem em desuso após D. João II no numerário de cobre. É também de sublinhar que as letras de cunho foram marcadas apenas em alguns Ceitis do reinado de D. Afonso V.

A tipologia da letra também é um barómetro fiável. Todos os numismas de D. Afonso V apresentam a letra Gótica, já no caso de D. João II, apenas algumas letras têm esse estilo sendo a maioria de tipo Renascentista. A partir de D. Manuel I já são apenas inscritas no estilo moderno.

- Castelo: O castelo enquanto característica mais distintiva da composição do Ceitil, não altera, durante os cinco reinados, a sua fisionomia de três torres onde a central é superior às restantes, estando estas rodeadas por uma muralha. O que muda ao longo do tempo é apenas o seu tamanho proporcionalmente às dimensões da moeda $\mathrm{e}$ o detalhe que apresenta. Vai perdendo altura de torres e ganhando altura na muralha. A dita muralha vai estrangulando cada vez mais as torres e vai adquirindo uma perspectiva mais frontal e menos aérea. As ameias vão sendo cada vez mais grosseiras e em menor número.

- Ondas: As ondas vão perdendo cada vez mais destaque. Inicialmente são feitas várias linhas onduladas a representar o mar onde o castelo assenta, mas com o passar do tempo estas vão sendo em menor número e comprimento, até desaparecerem completamente no reinado de D. Sebastião.

- Escudo: Também este vai perdendo detalhe ao longo dos reinados. Com D. Afonso V é um escudo de base pontiaguda sobre uma cruz de Avis com as cinco quinas e os quatro castelos. D. João II e D. Manuel I retiram a cruz de Avis e substituem por pequenos círculos em redor deste mantendo as demais características. D. João III já apresenta um escudo de base arredondada onde alguns exemplares já não têm os castelos. Com D. Sebastião, o escudo nunca apresenta castelos e já não contém círculos em seu redor.

Estes cinco pontos principais são os que sofreram alterações mais consideráveis ao longo do seu tempo de cunhagem, portanto devem ser procurados no pouco que é possível observar em Ceitis em mau estado de conservação de maneira a poder afinar as cronologias o mais possível. 
O Ceitil é sem dúvida um dos símbolos da modernidade portuguesa e europeia. O corte com a estética medieval mais religiosa para uma demonstração de globalidade e o fim da cunhagem em bolhão empobrecido para uma moeda de cobre estável, são as duas maiores evidências modernistas. Talvez a perda de pormenor e dimensão que a moeda vai apresentando seja directamente proporcional à importância que esta vai tendo no sistema monetário português desde a segunda metade século XV até ao terceiro quartel do século XVI. Com o andar do tempo o Ceitil foi sendo uma moeda com menor poder de compra e a partir do reinado de D. Manuel I foram acrescentadas outras tipologias de cobre para suprir as novas necessidades comerciais. Importa ainda referir que apesar desta sua gradual desvalorização o grande número de Ceitis registados em Lisboa e noutros locais de Portugal, Espanha, Europa e antigos territórios ultramarinos ibéricos, reflecte a sua incontornável importância no panorama económico.

\section{Bibliografia}

ARAGÃO, Teixeira de, 1875, "Descripção Geral e Histórica das moedas cunhadas em nome dos Reis, Regentes e Governadores de Portugal", tomo I, Lisboa: Imprensa Nacional.

BRAGA, Ferreira, 1903, "Numismática Portuguesa: O Ceitil de cobre", em "O Arqueólogo Português", série I, volume VIII, Lisboa: Imprensa Nacional, pp. 24-29.

CURADO, Tiago, 2015, "O Ceitil" in "Lisboa 1415 Ceuta", Ceuta: Papel de Aguas, pp. 172-173.

GODINHO, Vitorino Magalhães, 1981, "Os Descobrimentos e a Economia Mundial", volume 2, Lisboa: Presença.

GOMES, Alberto, 2007, "Moedas Portuguesas e do território que hoje é Portugal", Lisboa: Associação Numismática de Portugal.

LEÃO, Duarte Nunes, 1569, "Leis extravagantes", Lisboa: Antonio Gonçaluez.

MAGRO, Francisco A. Costa, 1986, "Ceitis", Sintra: Instituto de Sintra.

MATTOSO, José, 1997, "História de Portugal: A Monarquia Feudal (1096-1480)", volume 2, Lisboa: Editorial Estampa.

RESENDE, Garcia, 2007, "Vida e feitos d'El-Rey Dom João Segundo", Coimbra: Universidade de Coimbra.

VALÉRIO, Nuno, 2017, "Desvalorizações Monetárias na História de Portugal", Lisboa: Academia das Ciências de Lisboa.

VIEIRA, João Pedro, 2017, “A História do Dinheiro”, Lisboa: Academia das Ciências de Lisboa. 